\title{
DnaK, DnaJ, and GrpE heat shock proteins negatively regulate heat shock gene expression by controlling the synthesis and stability of $\sigma^{32}$
}

\author{
David Straus, ${ }^{1}$ William Walter, and Carol A. Gross \\ Department of Bacteriology, University of Wisconsin, Madison, Wisconsin 53706 USA
}

\begin{abstract}
The Escherichia coli DnaK heat shock protein has been identified previously as a negative regulator of $E$. coli heat shock gene expression. We report that two other heat shock proteins, DnaJ and GrpE, are also involved in the negative regulation of heat shock gene expression. Strains carrying defective dnaK, dnaJ, or grpE alleles have enhanced synthesis of heat shock proteins at low temperature and fail to shut off the heat shock response after shift to high temperature. These regulatory defects are due to the loss of normal control over the synthesis and stability of $\sigma^{32}$, the alternate RNA polymerase $\sigma$-factor required for heat shock gene expression. We conclude that DnaK, DnaJ, and GrpE regulate the concentration of $\sigma^{32}$. We suggest that the synthesis of heat shock proteins is controlled by a homeostatic mechanism linking the function of heat shock proteins to the concentration of $\boldsymbol{\sigma}^{32}$.
\end{abstract}

[Key Words: Heat shock proteins; DnaK heat shock gene expression; $\boldsymbol{\sigma}^{32}$ ]

Received August 9, 1990; revised version accepted September 12, 1990.

The induction of heat shock proteins following an abrupt increase in growth temperature has been observed in every cell type examined, including examples from eubacterial, archaebacterial, and eukaryotic organisms (Schlesinger et al. 1982; Craig 1985). Heat shock proteins are also induced by a variety of other stresses, including exposure to ethanol, UV irradiation, oxidative agents, viral infection, and the presence of abnormal proteins (for review, see Neidhardt and VanBogelen 1987). Recent work suggests that heat shock proteins provide functions that are essential in the control of protein folding (Chirico et al. 1988; Deshaies et al. 1988; Goloubinoff et al. 1989a; Gaitanaris et al. 1990), assembly (Goloubinoff et al. 1989b), and disassembly (Alfano and McMacken 1989; Dodson et al. 1989; Zylicz et al. 1989). It is likely that heat shock proteins carry out similar functions in most cells, as there is a high degree of sequence homology between heat shock proteins from widely divergent organisms (Bardwell and Craig 1984, 1987; McMullin and Hallberg 1988).

When Escherichia coli are shifted from low to high growth temperature, $\sim 17$ heat shock proteins are induced (Neidhardt and VanBogelen 1987). This induction is transient, peaking at $5-15 \mathrm{~min}$ after upshift and the dropping to a new steady-state rate of synthesis, which is characteristic of the new growth temperature. The expression of heat shock proteins, both at low temperature

1Present address: Howard Hughes Medical Institute, University of California School of Medicine, San Francisco, California 94143 USA. and after temperature upshift, depends on the function of the $r p o H(h t p R)$ gene (Neidhardt and VanBogelen 1981; Yamamori and Yura 1982; Zhou et al. 1988|. The product of this gene has been identified as a $\sigma$-factor, $\sigma^{32}$, which enables RNA polymerase to recognize the promoters for heat shock genes (Grossman et al. 1984; Cowing et al. 1985; Fujita et al. 1987). In addition to directing RNA polymerase to the heat shock genes, $\sigma^{32}$ also regulates their expression. A rapid and transient increase in the level of $\sigma^{32}$ is observed following temperature upshift, which can account for the induction of heat shock proteins (Lesley et al. 1987; Skelly et al. 1987; Straus et al. 1987). Additionally, artificial induction of $\sigma^{32}$ without a temperature shift results in the induction of heat shock proteins (Grossman et al. 1987). The increase in $\sigma^{32}$ level that accompanies a temperature upshift occurs as a result of changes in both the stability and synthesis of $\sigma^{32}$ (Straus et al. 1987). It is not known how an abrupt change in temperature causes an increase in the synthesis and stability of the alternate $\sigma$-factor.

Tilly et al. (1983) observed that a mutation in the dnaK heat shock gene resulted in enhanced heat shock gene expression at low temperature and an extended heat shock response after shift to high temperature, suggesting that DnaK is a negative regulator of the heat shock response. We have examined the phenotype of other heat shock gene mutants besides $d n a K$ and found that $d n a I$ and $g r p E$ mutants have a similar effect on heat shock gene expression. We have determined the mechanism for this effect; all three mutants are defective in 
the control of $\sigma^{32}$ synthesis and stability. These results indicate that heat shock gene expression is controlled by a negative feedback loop in which heat shock proteins regulate their own synthesis by controlling the level of $\sigma^{32}$. We suggest that temperature changes are sensed by this homeostatic regulatory mechanism through alteration in the function of DnaK, Dna), and GrpE.

\section{Results}

Expression of heat shock genes is enhanced in dnaJ and grpE mutants

The regulation of heat shock protein synthesis is altered in two ways in strains carrying the dnaK756 allele (Tilly et al. 1983). First, synthesis of heat shock proteins in these strains is increased during growth at $30^{\circ} \mathrm{C}$. Second, the shutoff phase of the heat shock response is delayed. To determine whether this effect is specific to the dnaK mutant, we examined the synthesis of heat shock proteins in strains carrying mutations in other heat shock genes. Our results indicate that of the strains analyzed, only mutations in $d n a$ I or grpE have a significant effect on heat shock protein synthesis.

Heat shock protein synthesis in the mutant strains was analyzed by two-dimensional gel electrophoresis of extracts from cells that had been pulse-labeled with radioactive amino acids at $30^{\circ} \mathrm{C}$ or at various times after shift to $42^{\circ} \mathrm{C}$. As compared to the parental strain, the dnaK756, dna/259, and grpE280 strains all showed a two- to fourfold increase in the $30^{\circ} \mathrm{C}$ synthesis rate of the four heat shock proteins analyzed. This effect was specific to the heat shock proteins, as the synthesis of EF-Tu (Table 1) and other non-heat shock proteins (data not shown/ was unaltered in the mutants. As is the case for dnaK756, the dnaJ259 and grpE280 mutants were also defective in the shutoff phase of the heat shock response following shift from 30 to $42^{\circ} \mathrm{C}$. As exemplified by the induction kinetics of the GroEL heat shock protein, each of the mutants show only a gradual drop in heat shock protein synthesis (Fig. 1). GroEL synthesis remains elevated for at least $60 \mathrm{~min}$ after temperature shift in the mutants. In wild-type cells, induction of GroEL is transient, peaking at $\sim 5$ min after temperature upshift. The shutoff of synthesis of the other heat shock proteins followed similar kinetics in the mutant strains (data not shown). These findings indicate that $d n a K$ is not the only heat shock gene involved in the regulation of heat shock protein synthesis. Mutations in the dnaI

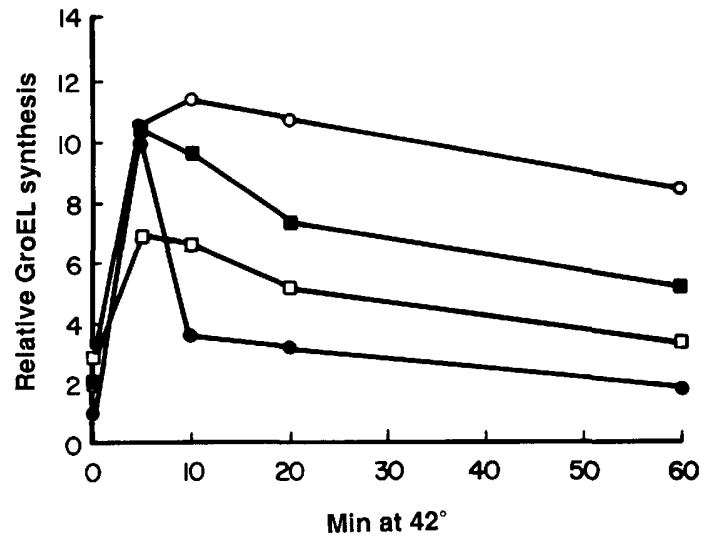

Figure 1. Shutoff of the heat shock response is defective in the dnaK756, grpE280, and dnal259 mutants. The relative synthesis of GroEL in wild-type (O), dnaK756 (O), grpE280 (অ), and dnal259( $\square$ ) strains was determined at $30^{\circ} \mathrm{C}$ or at 10,20 , and 60 min after shift to $42^{\circ} \mathrm{C}$ by pulse-labeling and two-dimensional gel electrophoresis, as described in Materials and methods. The synthesis rates are normalized to the $30^{\circ} \mathrm{C}$ wild-type rate. Shutoff of DnaK, HtpG, and HtpM synthesis was also defective in the mutants, and the relative magnitude of the defects in the different mutants was the same as that observed for GroEL synthesis.

and grpE heat shock genes also result in altered synthesis of heat shock proteins at both $30^{\circ} \mathrm{C}$ and during shutoff of the heat shock response.

Synthesis of heat shock proteins in strains carrying mutations in other heat shock genes was also examined. The lon146:: Tn10, groEL140, and groES30 alleles had only small effects on heat shock protein synthesis. These strains showed an increase of $~ 50 \%$ in heat shock protein synthesis at $30^{\circ} \mathrm{C}$ and exhibited only a slight delay in shutting off the heat shock response. Data for the lon $146:: \operatorname{Tn} 10$ strain is shown in Figure 2.

The induction of heat shock protein synthesis following temperature upshift is the result of increased heat shock gene transcription (Yamamori and Yura 1982; Taylor et al. 1984; Cowing et al. 1985). To determine whether altered heat shock gene expression in the mutants could be explained by altered rates of transcription, we examined derivatives of dnaK756, dna 259 , and grpE280, which carried a plasmid in which the expression of galactokinase is driven by the groE promoter. In these strains the rate of galactokinase synthesis indicates the rate of transcription initiation at the $g r o E$ pro-

Table 1. Heat shock protein synthesis is enhanced in heat shock gene mutants at $30^{\circ} \mathrm{C}$

\begin{tabular}{lrrrrr}
\hline & \multicolumn{1}{c}{ DnaK } & \multicolumn{1}{c}{ GroEL } & \multicolumn{1}{c}{ HtpG } & \multicolumn{1}{c}{ HtpM } & \multicolumn{1}{c}{ EF-Tu } \\
\hline Wild type & $1 \pm 0.03$ & $1 \pm 0.05$ & $1 \pm 0.01$ & $1 \pm 0.11$ & $1 \pm 0.06$ \\
dnaK756 & $1.93 \pm 0.04$ & $1.93 \pm 0.02$ & $2.28 \pm 0.15$ & $1.59 \pm 0.12$ & $0.95 \pm 0.01$ \\
grpE280 & $2.54 \pm 0.20$ & $2.07 \pm 0.03$ & $2.46 \pm 0.06$ & $1.82 \pm 0.20$ & $0.98 \pm 0.01$ \\
dnaJ259 & $4.40 \pm 0.33$ & $2.59 \pm 0.06$ & $4.03 \pm 0.20$ & $2.90 \pm 0.41$ & $1.00 \pm 0.01$ \\
\hline
\end{tabular}

The relative synthesis rate of the DnaK, GroEL, HtpG, and HtpM heat shock proteins and EF-Tu were determined in isogenic derivatives of $\mathrm{C} 600$, as described in Materials and methods. The rates for each protein are normalized to the rate of synthesis in the wild-type strain. The values are the average of triplicate determinations \pm the standard error. 


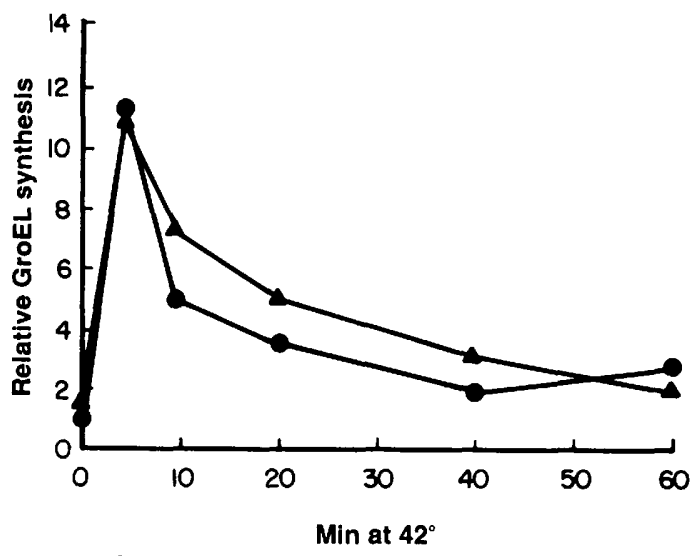

Figure 2. The heat shock response in the lon $146:: \operatorname{Tn} 10$ strain. The relative synthesis of GroEL in wild type (0) and lon $146:: \operatorname{Tn} 10(\mathbf{\Delta})$ was determined at $30^{\circ} \mathrm{C}$ or at 10,20 , and 60 min after shift to $42^{\circ} \mathrm{C}$, as described in Fig. 1. DnaK, $\mathrm{HtpG}$, and HtpM synthesis was similar to that shown for GroEL.

moter. Immunoprecipitation analysis indicated that following temperature upshift, induction of galactokinase synthesis was prolonged in the mutant strains compared to wild type (Fig. 3). These results indicate that the delayed shutoff of heat shock protein synthesis seen in the mutants following shift from 30 to $42^{\circ} \mathrm{C}$ results from increased transcription initiation at heat shock promoters. Additional experiments measuring the rate of $d n a K$ and dnaI mRNA synthesis by pulse-labeling with $\left[{ }^{3} \mathrm{H}\right]$ uridine and filter hybridization support this conclusion.

Increased expression of heat shock genes in the mutant strains at $30^{\circ} \mathrm{C}$ results from stabilization of $\sigma^{32}$

The major promoters of heat shock genes are recognized exclusively by $\sigma^{32}$-RNA polymerase (Cowing et al. 1985; Fujita et al. 1987; Zhou et al. 1988). The rate of transcription initiation at these promoters is limited by the amount of $\sigma^{32}$ (Grossman et al. 1987; Straus et al. 1987). Previous work has shown that the level of $\sigma^{32}$ is controlled by regulation of both its synthesis and stability (Straus et al. 1987). If either the stability or synthesis of $\sigma^{32}$ were increased in the mutants at low temperature, $\sigma^{32}$ would accumulate, thus explaining the overexpression of heat shock proteins in the mutant strains. We examined the stability of $\sigma^{32}$ by immunoprecipitation of the $\sigma$-factor from extracts of strains that were pulse-labeled at $30^{\circ} \mathrm{C}$ with $\left[{ }^{35} \mathrm{~S}\right]$ methionine and chased with unlabeled methionine. This analysis indicated that the mutants were impaired in their ability to degrade $\sigma^{32}$ (Fig. 4A). While $\sigma^{32}$ was degraded with a $t_{3 / 2}$ $\sim 1 \mathrm{~min}$ in the wild-type strain, $\sigma^{32}$ was degraded $10-$ to 20 -fold more slowly in the mutant strains. The grpE strain showed the largest effect on the rate of $\sigma^{32}$ degradation $\left(t_{1 / 2}>20 \mathrm{~min}\right)$, whereas the $d n a K$ and $d n a l$ strains had a more moderate effect $\left(t_{1 / 2}=10 \mathrm{~min}\right)$. Tilly et al. (1989) have also observed an effect of dnaK756 on the rate of $\sigma^{32}$ degradation. In contrast to the effects on $\sigma^{32}$ stability, immunoprecipitation analysis indicated that the mutants did not exhibit a significant increase in the synthesis of $\sigma^{32}$ at $30^{\circ} \mathrm{C}$ (data not shown). This reflects a null phenotype, because neither a $d n a K$ nor a $d n a I$ deletion mutant showed an increase in $\sigma^{32}$ synthesis at $30^{\circ} \mathrm{C}$ (data not shown). These data indicate that the increased transcription of heat shock genes observed in the dnaK, $d n a I$, and grpE strains at $30^{\circ} \mathrm{C}$ results solely from their inability to degrade $\sigma^{32}$ rapidly.

We measured the amount of $\sigma^{32}$ directly to confirm that the level of $\sigma^{32}$ increases in the mutant strains. As predicted from the stability measurements, the increase in $\sigma^{32}$ concentration in the mutants is actually greater than the increase in heat shock gene expression. Western blot analysis indicates that the level of $\sigma^{32}$ in the mutants is 10 - to 20 -fold greater at $30^{\circ} \mathrm{C}$ than in the wild-type strain (data not shown), whereas the synthesis of heat shock proteins in the mutants is only 2 - to 4 -fold greater than in the wild-type strain (Table 1). We have found that the apparent activity of $\sigma^{32}$ is decreased when there is an excess of heat shock proteins (Straus et al. 1989). The difference between the increase in $\sigma^{32}$ level and the increase in the heat shock gene expression in the mutants is probably due to negative regulation of $\sigma^{32} \mathrm{ac}-$ tivity. Initially, the enhanced stability of $\sigma^{32}$ in the mutants would cause a proportionate overproduction of heat shock proteins, but under steady-state conditions the activity of $\sigma^{32}$ would be decreased such that the increase in heat shock protein synthesis would be only a fraction of the increase in the level of $\sigma^{32}$.

Changes in both the stability and synthesis of $\sigma^{32}$ contribute to the altered heat shock response in the mutant strains

Changes in both the rates of degradation and synthesis of $\sigma^{32}$ normally contribute to the turn-on and shutoff of the heat shock response. We therefore determined

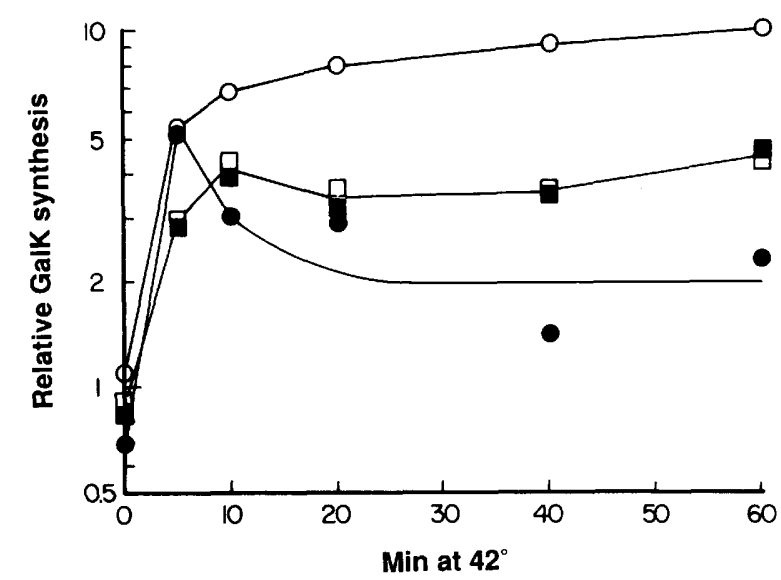

Figure 3. Transcription from the groE heat shock promoter is increased in the $\operatorname{dnaK}, \operatorname{grp} E$, and $d n a I$ mutants. Cultures of wild-type (O), dnaK756 (O), grpE280 (ロ), and dnaJ259 (口) strains carrying plasmid pDC441 were pulse-labeled with $\left.{ }^{[35} \mathrm{S}\right]$ methionine for $1 \mathrm{~min}$ either at $30^{\circ} \mathrm{C}$ or at $5,10,20,40$, and $60 \mathrm{~min}$ after shift to $42^{\circ} \mathrm{C}$. The synthesis of galactokinase relative to total protein synthesis was determined by immunoprecipitation, as described in Materials and methods. 
DnaK, DnaJ, and GrpE regulate concentration of $\boldsymbol{\sigma}^{32}$

A

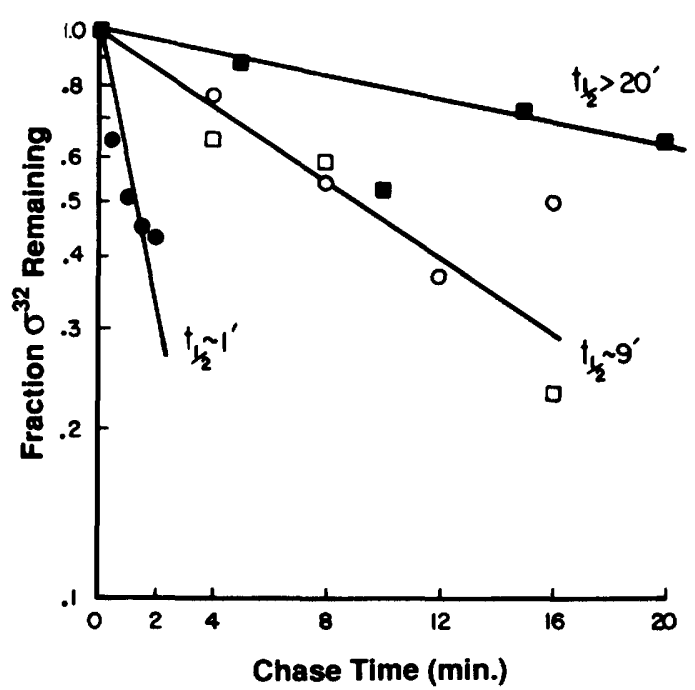

B

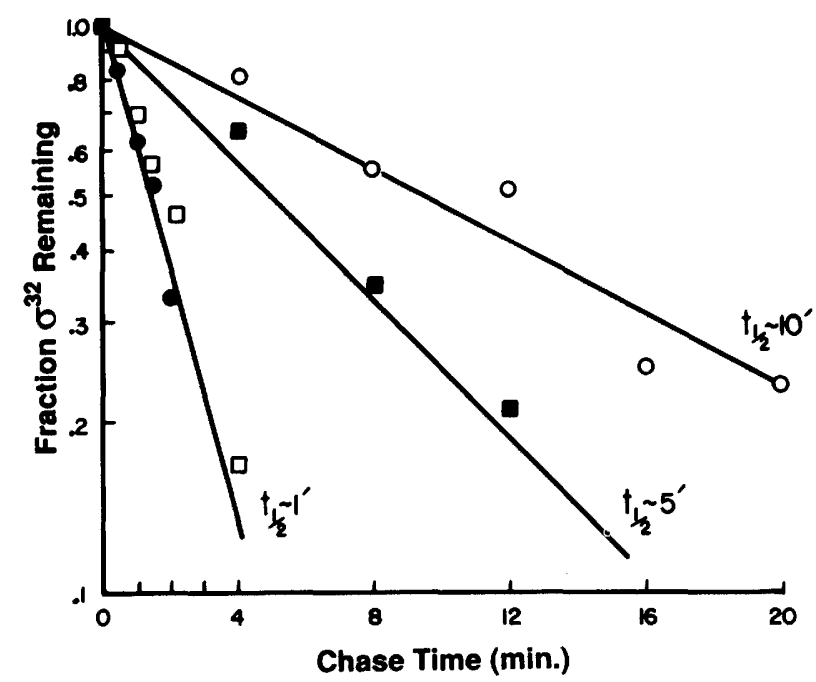

Figure 4. Degradation of $\sigma^{32}$ is defective in the dnaK756, grpE280, and dna/259 mutants. Stability of $\sigma^{32}$ in isogenic wild-type (O),

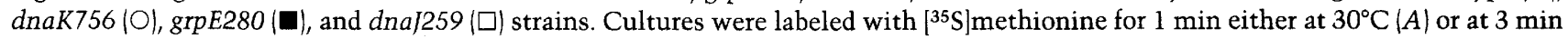
after shift from 30 to $42^{\circ} \mathrm{C}(B)$, and the fraction of $\sigma^{32}$ remaining at various times after addition of unlabeled methionine was determined by immunoprecipitation as described in Materials and methods. Approximate half-lives for $\sigma^{32}$ in the different strains are indicated.

whether either of these processes was altered in the mutants following temperature upshift. In contrast to the results at $30^{\circ} \mathrm{C}$, altered regulation of both synthesis and stability of $\sigma^{32}$ contribute to delayed shutoff after shift to $42^{\circ} \mathrm{C}$.

Each of the mutant strains affect the synthesis of $\sigma^{32}$ in much the same way that they alter the synthesis of heat shock proteins during the shutoff of the heat shock response. In wild-type strains, $\sigma^{32}$ synthesis is induced, peaks at 3-4 min after temperature upshift, and drops to a lower rate by $6 \mathrm{~min}$ after upshift. In the mutant strains the synthesis of $\sigma^{32}$ is induced normally but remains elevated up to $15 \mathrm{~min}$ after shift from 30 to $42^{\circ} \mathrm{C}$ (Fig. 5). Measurement of $\sigma^{32}$ stability during the shutoff phase of the heat shock response indicates that the prolonged heat shock response of the dnaK756 and grpE280 mutants is also due to an increase in $\sigma^{32}$ stability in these strains (Fig. 4B). In wild-type strains $\sigma^{32}$ is stable for the first 4 min following shift from 30 to $42^{\circ} \mathrm{C}$ and then returns to the rapid rate of degradation seen prior to temperature shift $\left(t_{1 / 2}=1 \mathrm{~min}\right)$. In contrast, the dnaK756 and grpE280 mutants continue to degrade $\sigma^{32}$ slowly $\left(t_{1 / 2}=5-10 \mathrm{~min}\right)$ during the shutoff phase of the heat shock response. Note that the dnaJ 259 mutant has no defect in $\sigma^{32}$ degradation at $42^{\circ} \mathrm{C}$; this strain exhibited the same rapid rate of $\sigma^{32}$ degradation as did the wild type during the shutoff phase of the heat shock response (Fig. 4B). Because a dnal deletion strain is also proficient in degradation of $\sigma^{32}$ at $42^{\circ} \mathrm{C}$, lack of a proteolysis phenotype cannot be explained by suggesting that the dna/259 allele is partially functional at $42^{\circ} \mathrm{C}$ (data not shown). In summary, the altered regulation of the heat shock proteins observed in the mutants after shift from 30 to $42^{\circ} \mathrm{C}$ results from an increase in both the synthesis and sta- bility of $\sigma^{32}$ in the dnaK756 and grpE280 strains. Altered regulation in the dnaJ259 mutant results solely from an increase in the rate of $\sigma^{32}$ synthesis, perhaps accounting for the fact that dnal mutants show less induction of

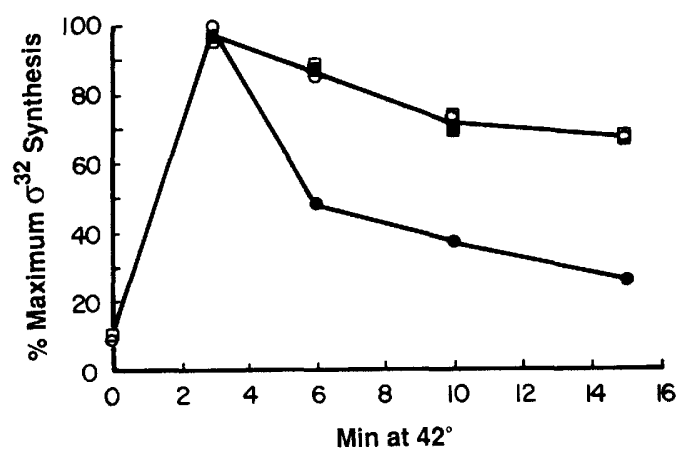

Figure 5. Repression of $\sigma^{32}$ synthesis during shutoff of the heat shock response is defective in the dnaK756, grpE280, and dna/259 mutants. Cultures of wild-type (1), dnaK756 (O), grpE280 (四), and dnaJ259 (口) strains were pulse-labeled with $\left.{ }^{35} \mathrm{~S}\right]$ methionine for $1 \mathrm{~min}$ either at $30^{\circ} \mathrm{C}$ or at $3,6,10$, and 15 min after shift to $42^{\circ} \mathrm{C}$. The synthesis of $\sigma^{32}$ relative to total protein synthesis was determined by immunoprecipitation, as described in Materials and methods, and corrected for a 2.5-fold increase in total protein synthesis following temperature upshift to derive the change in absolute synthesis. The values represent the average of at least four experiments normalized to the maximum rate of synthesis within each strain following temperature upshift. The average maximum increase in the rate of $\sigma^{32}$ synthesis was similar in all four strains: Wild type increased 11.1-fold while dnaK756, grpE280, and dnaJ259 increased 9.7-, 12.2-, and 9.5-fold, respectively. 
heat shock proteins after temperature upshift than $d n a K$ and grpE mutants (Fig. 1).

We have found previously that the transient induction of $\sigma^{32}$ synthesis that occurs following a shift from 30 to $42^{\circ} \mathrm{C}$ is due to translational regulation. This conclusion was based on two observations: (1) Induction of $\sigma^{32}$ synthesis is transient even when the synthesis of $\sigma^{32}$ is directed by the $\lambda p_{\mathrm{L}}$ promoter instead of the normal $\mathrm{rpoH}$ promoters (Grossman et al. 1987); and (2) correct regulation of an $r p o H-l a c Z$ fusion after temperature upshift requires that its expression be governed by $r p o H$ translational signals (Straus et al. 1987). Previously, we used the $\lambda p_{\mathrm{L}}$ fusion to $r p o H$ to demonstrate that the dnaK756 mutant was defective in this translational regulation (Grossman et al. 1987). We used the same $\lambda p_{\mathrm{L}}$ fusion to $r p o H$ to determine whether dnaJ259 and grpE280 alleles also affected translational regulation. Immunoprecipitation analysis indicated that synthesis of $\sigma^{32}$ in the wildtype strain peaked at $10 \mathrm{~min}$ following temperature upshift and was then repressed while synthesis of $\sigma^{32}$ in the mutants remained elevated following induction (Fig. 6). This finding indicates that the alteration in $\sigma^{32}$ synthesis observed in the heat shock gene mutants is probably due to a defect in translational regulation.

\section{Discussion}

Characterization of the $d n a K, d n a l$, and grpE mutants indicates that the DnaK, DnaJ, and GrpE heat shock proteins negatively regulate heat shock gene expression. The mutants exhibit increased expression of heat shock proteins at $30^{\circ} \mathrm{C}$ and fail to shut off the heat shock response after shift to high temperature. We have deter-

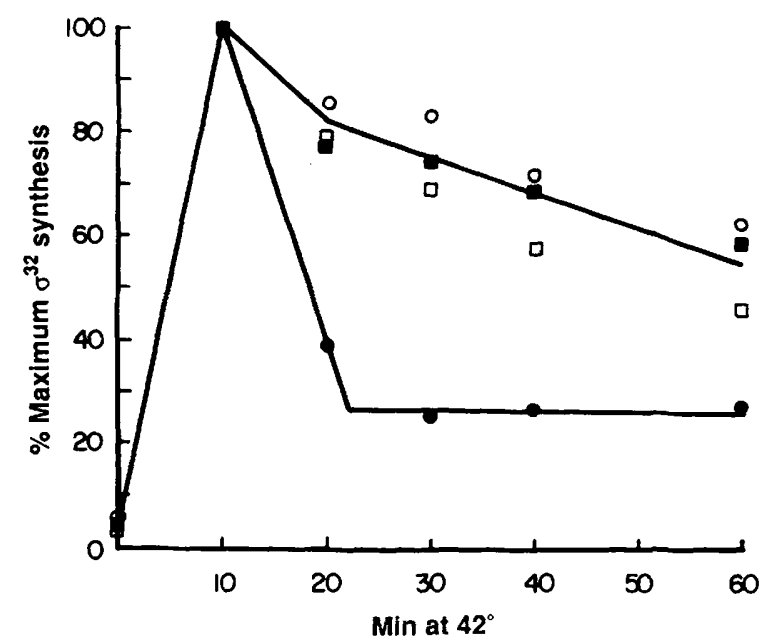

Figure 6. The dna756, grpE280, and dna/259 mutants are defective in regulation of $\sigma^{32}$ synthesis. The synthesis of $\sigma^{32} \mathrm{di}$ rected by the $\lambda p_{\mathrm{L}}$ promoter in wild-type (O), dnaK756 (O), grpE280 (口), and dna/259 (口) strains carrying plasmid pAG37 was determined at $30^{\circ} \mathrm{C}$ or at $10,20,30,40$, and 60 min after shift to $42^{\circ} \mathrm{C}$ by pulse-labeling and immunoprecipitation, as described in Materials and methods. The values for the synthesis of $\sigma^{32}$ within each strain are normalized to the maximum rate of synthesis following shift to $42^{\circ} \mathrm{C}$. mined the mechanism for these effects. In every case, the key regulatory feature is the overproduction of $\sigma^{32}$ in the mutants relative to the wild-type strain. Each of the mutant strains is defective in degrading $\sigma^{32}$ at $30^{\circ} \mathrm{C}$. The resultant accumulation of $\sigma^{32}$ leads to overexpression of heat shock proteins at low temperature. Tilly et al. (1989) have also found that $d n a K$ mutants are defective in degrading $\sigma^{32}$ at $30^{\circ} \mathrm{C}$. The mechanism underlying the delayed shutoff of the heat shock response after shift to high temperature is more complex. Each of the mutant strains continues synthesizing $\sigma^{32}$ at a high rate for an extended time after shift to $42^{\circ} \mathrm{C}$ because they are defective in translational regulation of $\sigma^{32}$ synthesis. In addition, the dnaK756 and grpE280 mutants are also defective in the degrading $\sigma^{32}$ at high temperature. As a consequence, $\sigma^{32}$ levels remain elevated for an extended time after temperature upshift in the mutants leading to a delay in the shutoff of the heat shock response.

Of the major heat shock proteins, DnaK, DnaJ, and GrpE appear to be uniquely involved in regulating the heat shock response because among the mutations tested, only mutations in these genes affect $\sigma^{32}$ synthesis and stability. It is possible that additional, yet-to-be discovered heat shock proteins will also be involved in regulating $\sigma^{32}$. DnaK, DnaJ, and GrpE have been thought to function together ever since their discovery as host proteins required for $\lambda$ replication. Biochemical analysis indicates that these proteins act in the formation of a productive initiation complex by disassembling an intermediate protein complex at the $\lambda$ origin of replication (Alfano and McMacken 1989; Dodson et al. 1989; Zylicz et al. 1989). These studies make it unlikely that these heat shock proteins are directly responsible for degrading $\sigma^{32}$ and/or regulating its synthesis. This viewpoint is supported by additional investigations demonstrating that DnaK, Dnal, and GrpE bind denatured or partially unfolded proteins such as $\lambda$ repressor (Gaitanaris et al. 1990). Thus, these three heat shock proteins probably alter the interactions between $\sigma^{32}$ and the proteins directly responsible for mediating its degradation and translational regulation. For example, DnaK, DnaJ, and GrpE could increase the degradation of $\sigma^{32}$ by maintaining it in a partially denatured state to facilitate the function of a protease.

The existence of a negative feedback loop coupling the function of heat shock proteins to the concentration of $\sigma^{32}$ suggests that a homeostatic mechanism is responsible for the regulation of heat shock gene expression. In such a model, the involvement of the DnaK, DnaJ, and GrpE proteins in the negative regulation of $\sigma^{32}$ synthesis and stability permits the cell to monitor whether the amount of these proteins is adequate for cell growth. In the simplest version of this model, the "thermometer" utilized by the cell is actually the free pool of the DnaK, DnaJ, and GrpE proteins themselves. An increase in growth temperature would deplete the "free pool" of DnaK, DnaJ, and GrpE as a consequence of an increased demand for these proteins. Some potential substrates that could transiently decrease the free pool of DnaK, DnaJ, and GrpE are newly synthesized proteins that are 
partially or completely unfolded, preexisting proteins that are partially denatured upon temperature upshift, and increased amounts of unstable proteins. As a result of the undersupply of the three heat shock proteins, cells would become defective in $\sigma^{32}$ degradation and translational regulation of $\sigma^{32}$ synthesis. This response would be self-limiting because increased levels of heat shock proteins would allow the cell to re-establish negative regulation of $\sigma^{32}$.

The regulation of $\sigma^{32}$ stability during the heat shock response is explained simply by a homeostatic mechanism; however, an additional postulate is required to explain how this mechanism can account for the transient derepression of $\sigma^{32}$ synthesis during the heat shock response. Because the DnaK, DnaI, and GrpE proteins are not required for regulation of $\sigma^{32}$ synthesis at low temperature, titration of heat shock protein function following temperature upshift, by itself, would be insufficient to explain the induction of $\sigma^{32}$ synthesis. An additional event must be responsible for making the regulation of $\sigma^{32}$ synthesis dependent on heat shock protein function at high temperature. As an example of such a mechanism, a translational repressor of $\sigma^{32}$ synthesis might be inherently temperature sensitive, becoming partially denatured upon shift to high temperature. In this case, accumulation of the DnaK, DnaJ, and GrpE heat shock proteins would then provide the functions necessary to renature the repressor and re-establish the repression of $\sigma^{32}$ synthesis required for shutoff of the heat shock response.

How likely is it that temperature is sensed by a homeostatic mechanism linking heat shock protein function to regulation? Two basic requirements of this model are that the heat shock proteins be present in limiting concentrations in the cell and that demand for heat shock proteins increases as the temperature rises. The fact that the maximum growth temperature of $E$. coli is directly correlated with the capacity to synthesize heat shock proteins indicates both that heat shock proteins are limiting and that more of them are required at higher growth temperatures (Yamamori and Yura 1982). The finding that increasing the amount of heat shock proteins either at 30 or $42^{\circ} \mathrm{C}$ increases the ability of cells to degrade puromycyl fragments at both temperatures is consistent with the idea that heat shock proteins are present in limiting concentration (Straus et al. 1988). Notably, addition of puromycin induces heat shock gene expression (Goff and Goldberg 1985), as would be expected if a homeostatic mechanism controls gene expression. Evidence that such a mechanism specifically involves DnaK, DnaJ, and GrpE comes from experiments with $\lambda$ repressor. Parsell and Sauer (1989) have demonstrated that the heat shock response is induced by overexpression of a mutated amino-terminal fragment of $\lambda$ repressor that is denatured but stable in E. coli at $30^{\circ} \mathrm{C}$. The Gottesman group has found that renaturation of $\lambda$ repressor is defective in $d n a K, d n a J$, and grpE mutant strains both in vivo and in crude extracts and that the in vitro defect is restored by extracts from wild-type cells suggesting that denatured $\lambda$ repressor is a substrate of
DnaK, DnaJ, and GrpE (Gaitanaris et al. 1990). Taken together, these experiments indicate a direct link between depletion of the free pool of DnaK, DnaJ, and GrpE and induction of the heat shock response.

Reports from several groups suggest that DnaK homologs, the Hsp70 proteins, play a special role in regulating the eukaryotic heat shock response. Early studies showed that when accumulation of functional Hsp70 protein was blocked, the heat shock genes were greatly overtranscribed (DiDomenico et al. 1982). More recent studies directly implicate $\mathrm{Hsp} 70$ as a negative regulator of the heat shock response. Underexpression of Hsp70, accomplished by disrupting the yeast SSA1 and SSA2 genes (encoding Hsp70 proteins) results in increased transcription of the heat-inducible SSA3 and SSA4 genes (Boorstein and Craig 1990; Stone and Craig 1990). Moreover, this increase is mediated by the heat shock element, the same DNA sequence responsible for the increased transcription observed during the heat shock response. Finally, recent studies from the Welch group suggest that while Hsp70 associates only transiently with newly synthesized proteins, it remains permanently associated with amino acid analog-containing proteins or protein fragments generated by puromycin (Beckmann et al. 1990). Because treatment with amino acid analogs or puromycin induces the synthesis of Hsp70, these experiments indicate that accumulation of an Hsp70 substrate is sufficient to induce the heat shock response. The cellular response to temperature upshift and many of the heat shock proteins themselves are conserved throughout evolution. It would be remarkable if the logic used by cells to sense temperature change had not also been conserved.

\section{Materials and methods}

\section{Strains}

Strains carrying dnaK756-thr :: Tn10, dna/259-thr :: Tn10, grpE280-tyrA:: Tn10, groES30-zid:: Tn10, and groEL140zjd :: $\operatorname{Tn} 10$ were from C. Georgopolous, and $\operatorname{lon} 146:: \operatorname{Tn} 10$ was from S. Gottesman. All of these alleles were transduced into a derivative of strain $\mathrm{C} 600$ (galK, leu, lacZX90, lacY, tonA, thi, thr, supE44/F'lacI ${ }^{\mathrm{q}}$, lacZ :: Tn5), using Plvir, selecting for tetracycline resistance, and scoring for temperature sensitivity, except for lon 146 transductants, which were selected for tetracycline resistance and examined for mucoidy. For the experiment in Figure 3, the dnaK756, dnaI259, and grpE280 alleles were transduced into a derivative of $\mathrm{C} 600$ carrying $\mathrm{pDC} 441$ and the $p c n B 8$ mutation (to reduce plasmid copy number) using P1vir, by selecting for the kanamycin resistance of a linked Tn10(kan) marker and scoring for temperature sensitivity. Plasmid pDC441 contains sequences from -60 to +77 of the groE promoter cloned into the SmaI site of plasmid pKOl such that expression galK is under control of the groE promoter. For the experiment in Figure 6, the dnaK756, dna/259, and grpE280 alleles were transduced into strain N5242 (bio, $\lambda c 1857, \triangle B A M$, $\Delta H 1, \Delta 8$ ) carrying pAG37. Plasmid pAG37 (Grossman et al. 1984 ) places expression of $r p o H$ under control of the $\lambda p_{\mathrm{L}}$ promoter. Strain PK101 carries a dnaKJ deletion, and strain PK102 carries a dnal deletion (Kang and Craig 1990). For the experiments investigating the null phenotype of these strains, MG1655 was used as the isogenic wild type. Strains were grown 
in M9-glucose media supplemented with all amino acids except those used for radiolabeling. Temperature upshifts were accomplished by rapidly transferring flasks from a $30^{\circ} \mathrm{C}$ shaking water bath to a $42^{\circ} \mathrm{C}$ shaking water bath.

\section{Protein synthesis}

The relative synthesis rates of heat shock proteins were determined by pulse-labeling and two-dimensional gel analysis. Cell culture aliquots of $0.5 \mathrm{ml}$ were pulse-labeled with $70 \mu \mathrm{Ci}$ of $\left[{ }^{3} \mathrm{H}\right]$ lysine for $1.5 \mathrm{~min}$, chased with an excess of unlabeled lysine for $1 \mathrm{~min}$, and sampled directly into $0.5 \mathrm{ml}$ of $10 \%$ trichloroacetic acid (TCA). Samples were analyzed by two-dimensional gel electrophoresis (O'Farrell 1975), following the addition of aliquots of cell lysate from $\left[{ }^{35} \mathrm{~S}\right]$ methionine-labeled cultures, which served as an internal standard for double-label quantitation of the heat shock proteins. The radioactive protein spots were excised from the two-dimensional gels, solubilized, and counted. The synthesis rates of the DnaK, GroEL, HtpG (C62.5), and HtpM (F84.1) heat shock proteins and EF-Tu were determined relative to total protein synthesis as described previously (Grossman et al. 1987).

\section{$\sigma^{32}$ synthesis and stability}

The synthesis and stability of $\sigma^{32}$ was determined by pulse-labeling and immunoprecipitation as described previously (Straus et al. 1987). For measurements of the relative synthesis rate of $\sigma^{32}, 1-\mathrm{ml}$ aliquots of cell culture were labeled with $70 \mu \mathrm{Ci}$ of $\left[{ }^{35} \mathrm{~S}\right] \mathrm{methionine}$ for $1 \mathrm{~min}$ and sampled directly into $0.11 \mathrm{ml}$ of $50 \%$ TCA. For measurements of $\sigma^{32}$ stability, cultures were labeled with $70 \mu \mathrm{Ci} / \mathrm{ml}\left[{ }^{35} \mathrm{~S}\right]$ methionine for $1 \mathrm{~min}$ and chased with excess unlabeled methionine, and 1-ml aliquots were sampled directly into TCA. $\sigma^{32}$ was immunoprecipitated from aliquots of each sample representing equal counts per minute. As a correction for losses in the immunoprecipitation analysis, equal amounts of a mutant $\sigma^{32}$ protein, which migrates more rapidly than the wild-type protein, were added to each sample. The mutant protein was supplied from a lysate of an $\left[{ }^{35} \mathrm{~S}\right] \mathrm{methi}-$ onine labeled strain that overproduces the mutant protein. Background estimates were made from samples of a wild-type culture that had been pulse-labeled and chased for $20 \mathrm{~min}$ during which time $>99 \%$ of the $\sigma^{32}$ is degraded. The immunoprecipitates were analyzed on SDS-polyacrylamide gels and the $\sigma^{32}$ bands were excised and counted.

\section{Galactokinase synthesis}

Galactokinase synthesis was determined by pulse-labeling and immunoprecipitation, as described previously (Straus et al. 1987), except that aliquots of mid-log phase cultures were labeled with $20 \mu \mathrm{C}$ of $\left[{ }^{35} \mathrm{~S}\right]$ methionine and that the ratio of counts per minute in the standard cells (labeled with $\left[{ }^{3} \mathrm{H}\right)$ leucine and $\left[{ }^{3} \mathrm{H}\right]$ lysine/ to the experimental cells was $0.25: 1$.

\section{Acknowledgments}

We thank C. Georgopoulos for providing numerous strains, B. $\mathrm{Craig}$ and $\mathrm{H}$. Echols for their excellent suggestions, and $\mathrm{Na}$ tional Institutes of Health grant R01GM-36278 for supporting this work.

The publication costs of this article were defrayed in part by payment of page charges. This article must therefore be hereby marked "advertisement" in accordance with 18 USC section 1734 solely to indicate this fact.

\section{References}

Alfano, C. and R. McMacken. 1989. Heat shock protein-mediated disassembly of nucleoprotein structures is required for the initiation of bacteriophage $\lambda$ DNA replication. J. Biol. Chem. 264: 10709-10718.

Bardwell, J.C.A. and E.A. Craig. 1984. Major heat shock gene of Drosophila and the Escherichia coli heat-inducible dnaK gene are homologous. Proc. Natl. Acad. Sci. 81: 848-852.

1987. Eukaryotic $\mathrm{Mr}-83,000$ heat shock protein has a homologue in Escherichia coli. Proc. Natl. Acad. Sci. 84: $5177-5181$.

Beckmann, R.P., L.A. Mizzen, and W.J. Welch. 1990. Interaction of Hsp70 with newly synthesized proteins: Implications for protein folding and assembly. Science 248: 850854.

Boorstein, E.R. and E.A. Craig. 1990. Transcriptional regulation of SSA3, an HSP70 gene from Saccharomyces cerevisiae. Mol. Cell. Biol. 10: 3262-3267.

Chandrasekhar, G., K. Tilly, C. Woolford, R. Hendrix, and C. Georgopoulos. 1986. Purification and properties of the GroES morphogenetic protein of Escherichia coli. I. Biol. Chem. 261: 12414-12419.

Chirico, W.J., M.G. Waters, and G. Blobel. 1988. 70K heat shock related proteins stimulate protein translocation into microsomes. Nature 332: 805-810.

Cowing, D.W., J.C.A. Bardwell, E.A. Craig, C. Woolford, R.W. Hendrix, and C. Gross. 1985. Consensus sequence for Escherichia coli heat-shock gene promoters. Proc. Natl. Acad. Sci. 80: $2679-2683$.

Craig, E.A. 1985. The heat shock response. Crit. Rev. Biochem. 18: $239-280$.

Deshaies, R.J., B.D. Koch, M. Werner-Washburne, E.A. Craig, and R. Schekman. 1988. A subfamily of stress proteins facilitates translocation of secretory and mitochondrial precursor polypeptides. Nature 332: 800-805.

DiDomenico, B.J., G.E. Bugaisky, and S. Lindquist. 1982. The heat shock response is self-regulated at both the transcriptional and post-transcriptional levels. Cell 31: 593-603.

Dodson, M., R. McMacken, and H. Echols. 1989. Specialized nucleoprotein structures at the origin of replication of bacteriophage $\lambda$. J. Biol. Chem. 264: 10719-10725.

Fuiita, N., T. Nomura, and A. Ishihama. 1987. Promoter selectivity of Escherichia coli RNA polymerase. 1. Biol. Chem. 262: 1855-1859.

Gaitanaris, G.A., A.G. Papavassiliou, P. Rubock, S.J. Silverstein, and M.E. Gottesman. 1990. Renaturation of denatured $\lambda$ repressor requires heat shock proteins. Cell 61: 10131020 .

Goloubinoff, P., A.A. Gatenby, and G.H. Lorimer. 1989a. GroE heat-shock proteins promote assembly of foreign prokaryotic ribulose bisphosphate carboxylase oligomers in Escherichia coli. Nature 337: 44-47.

Goloubinoff, P., J.T. Christeller, A.A. Gatenby, and G.H. Lorimer. 1989b. Reconstitution of active dimeric ribulose bisphophate carboxylase from an unfolded state depends on two chaperonin proteins and Mg-ATP. Nature 342: 884889.

Goff, S.A. and A.L. Goldberg. 1985. Production of abnormal proteins in E. coli stimulates transcription of lon and other heat shock genes. Cell 41: 587-595.

Grossman, A.D., J.W. Erickson, and C.A. Gross. 1984. The htpR gene product of $E$. coli is a sigma factor for heat-shock promoters. Cell 38: 383-390.

Grossman, A.D., D.B. Straus, W.A. Walter, and C.A. Gross. 1987. $\sigma^{32}$ synthesis can regulate the synthesis of heat shock proteins in Escherichia coli. Genes Dev. 1: 179-184.

Kang, P.J. and E.A. Craig. 1990. Identification and characterization of a new Escherichia coli gene that is dosage-dependent 
suppressor of a dnaK deletion mutation. I. Bacteriol. 172: 2055-2064.

Keller, J. and L. Simon. 1988. Divergent effects of a dnaK mutation on abnormal protein degradation in Escherichia coli. Mol. Microbiol. 2: 31-4l.

Lesley, S., N. Thompson, and R. Burgess. 1987. Studies of the role of the Escherichia coli heat shock regulatory protein $\sigma^{32}$ by the use of monoclonal antibodies. I. Biol. Chem. 262: 5404-5407.

McMullin, T. and R. Hallberg. 1988. A highly evolutionarily conserved mitochondrial protein is structurally related to the protein encoded by the Escherichia coli groEL gene. Mol. Cell. Biol. 8: 371-380.

Neidhardt, F.C. and R.A. VanBogelen. 1981. Positive regulatory gene for temperature-controlled proteins in Escherichia coli. Biochem, Biophys. Res. Commun. 100: 894-900.

- 1987. Heat shock response. In Escherichia coli and Salmonella typhimurium (ed. F.C. Neidhardt), pp. 1334-1345. American Society for Microbiology, Washington D.C.

O'Farrell, P.H. 1975. High resolution two-dimensional electrophoresis of proteins. I. Biol. Chem. 250: 4007-4021.

Parsell, D.A. and R.T. Sauer. 1989. Induction of a heat shocklike response by an unfolded protein in Escherichia coli: Dependence on protein level not protein degradation. Genes Dev. 3: 1226-1232.

Rothman, J.E. 1989. Polypeptide chain binding proteins: Catalysts of protein folding and related processes in cells. Cell 59: $591-601$.

Schlesinger, M.J., M. Ashburner, and A. Tissieres, eds. 1982. Heat shock: From bacteria to man. Cold Spring Harbor Laboratory, Cold Spring Harbor, New York.

Skelly, S., T. Coleman, C.F. Fu, N. Brot, and H. Weissbach. 1987. Correlation between the $32-\mathrm{kDa} \sigma$ factor levels and in vitro expression of Escherichia coli heat shock genes. Proc. Natl. Acad. Sci. 84: 8365-8369.

Stone, D.E. and E.A. Craig. 1990. Self-regulation of 70-kilodalton heat shock proteins in Saccharomyces cerevisiae. Mol. Cell. Biol. 10: 1622-1632.

Straus, D.B., W.A. Walter, and C.A. Gross. 1987. The heat shock response of $E$. coli is regulated by changes in the concentration of $\sigma^{32}$. Nature 329: 348-351.

. 1988. Escherichia coli heat shock gene mutants are defective in proteolysis. Genes Dev. 2: 1851-1858.

1989. Activity of $\sigma^{32}$ is reduced under conditions of excess heat shock protein production in Escherichia coli. Genes Dev. 2: 1851-1858.

Taylor, W.E., D.B. Straus, A.D. Grossman, Z.F. Burton, C.A. Gross, and R. Burgess. 1989. Transcription from heat-inducible promoter causes heat shock regulation of the sigma subunit of E. coli RNA polymerase. Cell 38: 371-381.

Tilly, K. and C. Georgopoulos. 1982. Evidence that the two Escherichia coli groE morphogenetic gene products interact in vivo. J. Bacteriol. 149: 1082-1088.

Tilly, K., N. McKittrick, M. Zylicz, and C. Georgopoulos. 1983. The DnaK protein modulates the heat shock response of Escherichia coli. Cell 34: 641-646.

Tilly, K., J. Spence, and C. Georgopoulos. 1989. Modulation of stability of the Escherichia coli heat shock regulatory factor $\sigma^{32}$. I. Bacteriol. 171: 1585-1589.

Yamamori, T. and T. Yura. 1982. Genetic control of heat-shock protein synthesis and its bearing on growth and thermal resistance in Escherichia coli K12. Proc. Natl. Acad. Sci. 79: $860-864$.

Zhou, Y.N., N. Kusukawa, J. Erickson, C. Gross, and T. Yura. 1988. Isolation and characterization of Escherichia coli mu- tants that lack the heat shock sigma factor $\sigma^{32} . J$. Bacteriol. 170: 3640-3649.

Zylicz, M., D. Ang, K. Liberek, and C. Georgopoulos. 1989. Initiation of $\lambda$ DNA replication with purified host- and bacteriophage-encoded proteins: The role of the DnaK, Dnal and GrpE heat shock proteins. EMBO I. 8: 1601-1608. 


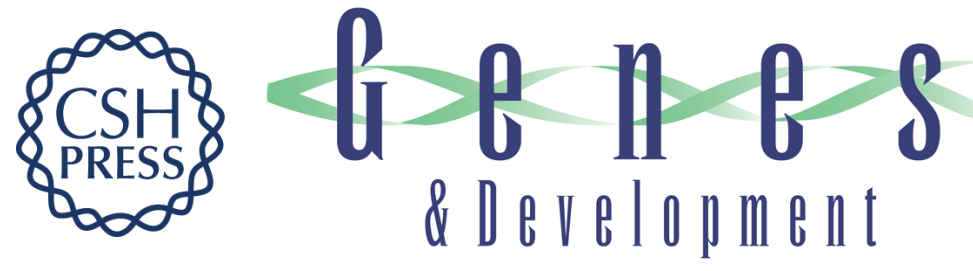

\section{DnaK, DnaJ, and GrpE heat shock proteins negatively regulate heat shock gene expression by controlling the synthesis and stability of sigma 32.}

D Straus, W Walter and C A Gross

Genes Dev. 1990, 4:

Access the most recent version at doi:10.1101/gad.4.12a.2202

References This article cites 39 articles, 21 of which can be accessed free at:

http://genesdev.cshlp.org/content/4/12a/2202.full.html\#ref-list-1

License

Email Alerting

Service

Receive free email alerts when new articles cite this article - sign up in the box at the top right corner of the article or click here.

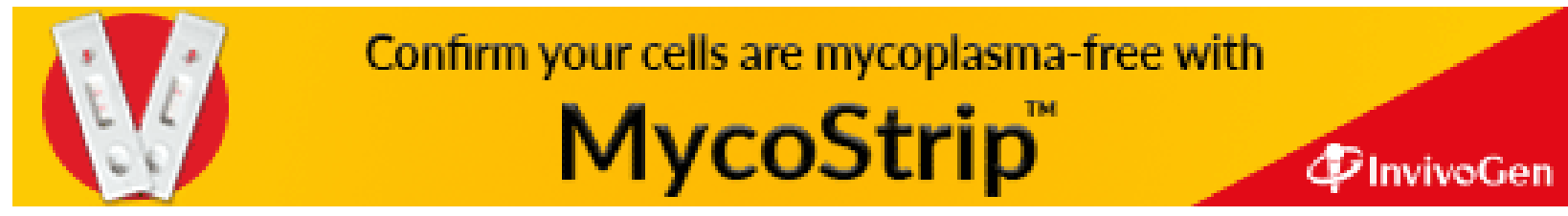

